\title{
Agronegócio da citricultura sergipana entre 2010 a 2017
}

\author{
Airan Miguel Dos Santos Panta $^{1} \&$ Valter Rubens Alcantara Santos Sobrinho ${ }^{2}$ \\ RESUMO
}

\begin{abstract}
O mercado citrícola do Brasil participa com 34\% da produção mundial. Gera cerca de 200 mil empregos diretos e indiretos e o setor ainda produz um PIB de US\$ 6,5 bilhões de dólares em todos os elos da sua cadeia produtiva. O estado de Sergipe, o menor da federação, é o quarto maior produtor de citros do País, contribuindo com 453 mil toneladas de frutos em 2017. O objetivo do trabalho foi analisar a evolução da área plantada, a produção e produtividade de laranja no estado de Sergipe e os fatores que impactaram seu cultivo, nos últimos cinco anos, de 2010 a 2017. A área destinada ao cultivo de laranja variou de 54.733 ha em 2010 para a 47.442 ha em 2017, correspondente a $32,7 \%$ e $6,4 \%$ da área plantada no Nordeste e no Brasil, respectivamente. Ao longo desses anos observa-se que apesar da área total plantada no país ter diminuído, a área plantada no Nordeste praticamente manteve-se estável, com os números em 2010 de 125.068 ha e em 2017 de 122.807 ha. No estado de Sergipe, em 2010, foram colhidas 805.962 toneladas enquanto que em 2017, apenas 453.933 toneladas, apresentando uma retração significativa de $43,7 \%$ na produção. Dentre os fatores que contribuem para essas oscilações temos a irregularidade climática, ataque de pragas chaves e os reduzidos investimentos que vêm sendo destinados à citricultura. Observou-se o decréscimo da produção de 821.940 para 626.440 toneladas, entre os anos de 2012 e 2013 respectivamente, evidenciando uma redução de $23,8 \%$ em apenas um ano. No ano de 2012 houve uma retração no acumulado de chuvas, apenas $752,3 \mathrm{~mm}$, sendo este valor $36,3 \%$ menor que o acumulado de 2011 . Percebe-se que o período coincide com a entrada da praga Aleurocanthus woglumi nos pomares sergipanos e uma baixa no volume de chuvas.
\end{abstract}

Temos de indexação: área cultivada, laranja, custo, preço, produtividade, citrus.

\section{Agribusiness of citrus industry in Sergipe, Brasil between 2010 and 2017}

\begin{abstract}
Brazil's citrus market accounts for $34 \%$ of world production. It generates about 200 thousand direct and indirect jobs and the sector still produces a GDP of US $\$ 6.5$ billion in all links of its production chain. The state of Sergipe, the smallest of the federation, is the fourth largest citrus producer in the country, contributing 453 thousand tons of fruits in 2017. The objective of this work was to analyze the evolution of planted area, production and productivity of orange in the state.
\end{abstract}

\footnotetext{
${ }^{1}$ Programa de Pós-graduação em Agricultura e Biodiversidade, Universidade Federal de Sergipe - UFS, São Cristóvão, SE, Brasil ${ }^{2}$ Departamento de Engenharia Agronômica, Universidade Federal de Sergipe - UFS, São Cristóvão, SE, Brasil

Autor correspondente: Airan Miguel dos Santos Panta, Programa de Pós-graduação em Agricultura e biodiversidade, Universidade Federal de Sergipe - UFS, Av. Marechal Rondon, s/n - Jardim Rosa Elze, CEP 49100-000, São Cristóvão - SE. Email: airanmiguel@gmail.com
} 
Sergipe and the factors that impacted its cultivation over the past five years from 2010 to 2017 . The area for orange cultivation ranged from 54,733 ha in 2010 to 47,442 ha in 2017 , corresponding to $32.7 \%$ and $6.4 \%$ of planted area in the Northeast and Brazil, respectively. Throughout these years, it is observed that although the total planted area in the country has decreased, the planted area in the Northeast has remained practically stable, with the numbers in 2010 of 125,068 ha and in 2017 of 122,807 ha. In the state of Sergipe, in 2010, 805,962 tons were harvested while in 2017 , only 453,933 tons, with a significant retraction of $43.7 \%$ in production. Among the factors that contribute to these fluctuations are climate irregularity, attack by key pests and the small investments that have been earmarked for citrus. The production decreased from 821,940 to 626,440 tons between 2012 and 2013 respectively, showing a reduction of $23.8 \%$ in just one year. In 2012 there was a decrease in the accumulated rainfall of only $752.3 \mathrm{~mm}$, which is $36.3 \%$ lower than in 2011. It can be seen that the period coincides with the entry of the Aleurocanthus woglumi pest in the Sergipe and orchards. a drop in rainfall.

Index terms: acreage, orange, cost, price, productivity, citrus.

\section{INTRODUÇÃO}

A citricultura existe em quase todos os municípios brasileiros e é um importante segmento da agricultura brasileira que engloba o cultivo das laranjas, tangerinas, limões, limas ácidas, limas doces, pomelos, cidras, laranjas azedas e toranjas, consumidos na forma de sucos, doces, compotas, geleias, licores e in natura, sendo o Brasil maior produtor mundial de laranjas (FAO, 2017).

A importância da citricultura vai além da geração de divisas para a economia brasileira, tendo grandes impactos na criação de empregos, na formação de capital, na geração de renda, na agregação de valor e, também, no desenvolvimento regional (FUNDECITRUS, 2016). Em 2017 foram produzidas 414 milhões de caixas de $40,8 \mathrm{~kg}$, equivalentes a 16,9 milhões de toneladas. Gerando cerca de 200 mil empregos diretos e indiretos e o setor ainda produz um PIB de US\$ 6,5 bilhões de dólares em todos os elos da sua cadeia produtiva. O Brasil tem exportado suco de laranja regularmente para cerca de 50 países (Brasil, 2018). Sua participação nas exportações mundiais no ano 2016/17 está estimada pelo USDA (2018) em 76\%. Em nível nacional, a maior parte da produção está concentrada no Estado de São Paulo, que produz cerca de 12,3 milhões de toneladas de laranja, o que representa $73 \%$ da produção nacional (IBGE, 2017). Sergipe é considerado o quarto maior produtor de laranja no Brasil, com uma produção de aproximadamente 453 mil toneladas de frutos em 40 mil hectares (IBGE, 2017).

A citricultura se destaca como um dos principais produtos agrícolas de Sergipe, contribuindo ao redor de $3 \%$ do PIB estadual, sendo o suco seu principal produto. Os pomares estão concentrados em aproximadamente 11.000 estabelecimentos agropecuários, a maioria de base familiar, localizados, predominantemente no sul do estado, na região dos Tabuleiros Costeiros (Figura 1). Ocupam uma área de 5,4 mil km², compreendendo os municípios de Arauá, Boquim, Cristinápolis (maior produtor), Estância, Indiaroba, Itaporanga d'Ajuda, Itabaianinha, Lagarto, Pedrinhas, Riachão do Dantas, Salgado, Tomar do Geru, Umbaúba e Santa Luzia do Itanhy (EMBRAPA, 2015). A média de produtividade de citros na região é 11,3 t/ha (IBGE, 2017), contudo encontram-se pomares conduzidos com tecnologias adequadas, com irrigação, produzindo entre 35 a 40 t/ha e com vida útil que varia de 10 a 15 anos (IBGE, 2017; Citrus BR, 2016).

$\mathrm{O}$ estado de Sergipe contribui, nacionalmente, com $6,4 \%$ da área colhida e com $2,4 \%$ da produção de laranjas. O resultado é que, com participação de 3\% do PIB sergipano, a cultura dos citros se destaca como um dos principais produtos agrícolas do estado. Além disso, dispõe de um considerável parque agroindustrial de esmagamento de laranja com duas fábricas, uma no município de Estância e outra em Boquim. A produção de citros é o principal produto da balança comercial de exportação de Sergipe. O produto sergipano é competitivo no mercado, pois o custo de produção é menor e as pragas são menos frequentes que no Sudeste (FAEP, 2016). No entanto, mesmo com certas ressalvas, percebe-se a dinâmica da citricultura sergipana num horizonte temporal com dois momentos distintos e marcantes: num deles, 1984, de pujante desempenho do setor citrícola de Sergipe e, no outro, 2007/08, em plena crise, que vem se arrastando desde a década de 1990 (Lopes \& Costa, 2009).

Da laranja, além do suco são extraídos óleos essenciais e componentes aromáticos. O bagaço de citros, com alto teor energético, é um coproduto industrial de expressivo valor econômico, para alimentação animal, sobretudo para ruminantes e, em especial, bovino de leite(EMBRAPA, 2015).

Apesar dos múltiplos usos, no período compreendido entre 2003 a 2015 foi verificada queda de $19,4 \%$ no consumo de suco de laranja, o que representa 640,8 milhões de caixas 


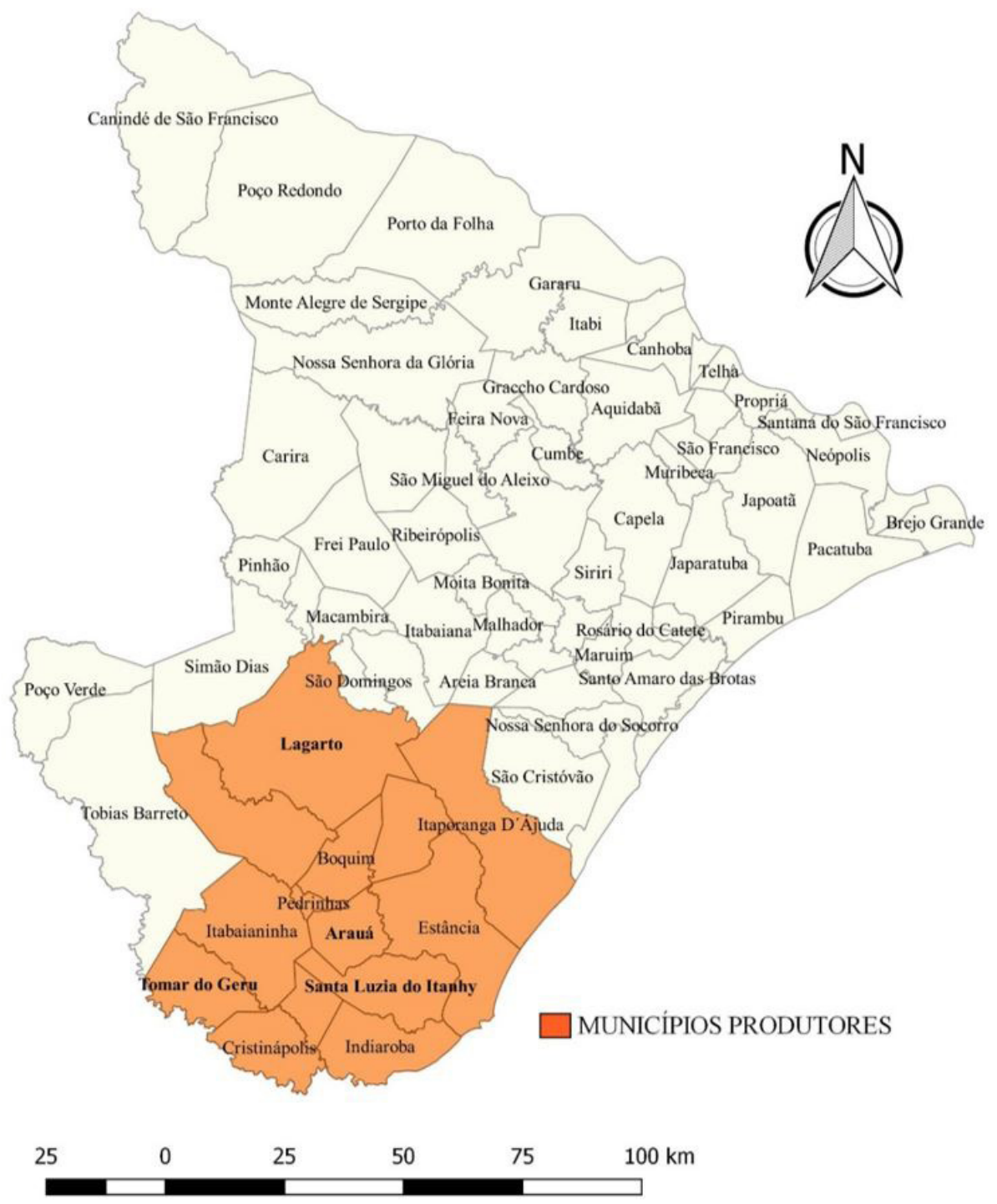

Figura 1. Cinturão citrícola sergipano, composto por 14 munícipios produtores.

Fonte: IBGE e SEMAH. Autor: Airan Miguel, 2018.

no período, equivalentes a cerca de 60 milhões de caixas de laranja a menos por ano (Neves \& Trombin, 2016). A queda no consumo interfere no balanço entre oferta e demanda, refletindo em aumento dos estoques de suco na indústria, redução nas exportações do suco brasileiro e, consequentemente, no preço da fruta (Boteon et al., 2013, 2015).

Em nível local, um grande desafio da citricultura sergipana é a mosca-negra-dos-citros, Aleurocanthus woglumi, que é considerada por agricultores e técnicos locais, indubitavelmente, a praga mais devastadora. A mosca negra apresenta hábito alimentar polífago e possui mais de 300 plantas hospedeiras, dentre elas plantas cultivadas, principalmente do gênero Citrus, ornamentais e daninhas. Os hospedeiros primários de $A$. woglumi são as plantas de citros, caju e abacate nas regiões pantropicais (Oliveira et al., 1999). O ciclo de ovo a adulto é de 45 a 133 dias. A praga (ninfa e adulto) se alimenta de floema, sendo que os adultos se concentram em brotações (Raga \& Costa, 2013), principalmente nas horas com temperaturas amenas. A dispersão de $A$. woglumi se dá verticalmente na planta e horizontalmente entre plantas. Entretanto, a forma antrópica de dispersão é a principal, ocorrendo através de mudas ou plantas ornamentais infestadas transportadas 
pelo homem, embora possa ocorrer naturalmente através de folhas infestadas carregadas pelo vento ou dispersão natural pelo crescimento populacional da praga (Silva, 2005). No entanto há unanimidade entre os cientistas em definir o transporte de plantas (mudas) como o principal meio de dispersão da praga.

A. woglumi é amplamente distribuída pelo mundo e foi relatada pela primeira vez no Brasil em julho de 2001 (Raga \& Costa, 2013), na região metropolitana de Belém (PA). Desde então parece ter havido rápida disseminação da praga para outros estados e regiões do país. A Coordenação de Defesa Vegetal do Estado de Sergipe informa sobre esta ocorrência desta praga, em 2013, atacando Citros (Citrus spp.), manga (Mangifera indica), pimenta (Capsicum frutescens), plantas ornamentais, fruta pão (Artocarpus altilis), banana (Musa spp), caju (Anacardium occidentale), jambo (Syzygium jambos) e pitanga (Eugenia uniflora). Relata que os transtornos já estão comprovados pela dificuldade de controle e por afetar municípios localizados na área de produção de citros (Andrade, 2014 apud Maciel, 2015). A maioria dos estados adota procedimentos da legislação federal para fiscalização quarentenária e somente os Estados de Minas Gerais, São Paulo, Bahia e Ceará possuem legislação estadual complementar à legislação federal.

Assim, este trabalho teve como objetivo analisar a evolução da área, produção e produtividade, bem como os principais fatores que podem ter impactado o cultivo de laranja no período de 2010 a 2017.

\section{MATERIAL E MÉTODOS}

Foram coletados os dados disponibilizados dos últimos oito anos (2010 a 2017), relativos a área destinada ao cultivo (mil ha), produção de frutos (mil toneladas) e produtividade (em t ha-1) de laranja no Estado de Sergipe. Foram utilizados artigos científicos, artigos de revistas do setor citrícola e dados estatísticos oficiais do Instituto Brasileiro de Geografia e Estatística (IBGE) e dados dos boletins de pesquisa agropecuária Empresa de Desenvolvimento Agropecuário de Sergipe (EMDAGRO).

Os dados coletados foram tabulados em planilha eletrônica utilizando o software Microsoft Excel 2016. Após as análises de regressão, foram confeccionados gráficos com as respectivas linhas de tendência, equações da reta e coeficientes de determinação (R2). Utilizou a Função TENDÊNCIA do Excel, que gera valores em uma tendência linear. Cria uma linha (usando o método de quadrados mínimos) às matrizes usando valores conhecidos "Y" e valores conhecidos "X". Retorna valores " $Y 2$ " em uma linha para a matriz de novos valores. É possível usar TENDÊNCIA para um ajuste de curva polinomial fazendo a regressão da mesma variável elevada a diferentes potências. (Microsoft Support Office, 2018).

\section{RESULTADOS E DISCUSSÕES}

Até meados da primeira década deste século, a produção citrícola esteve em expansão. Entre 1975 e 1990, a citricultura sergipana viveu o apogeu econômico contando com 50 mil hectares (EMBRAPA, 2007). Após esse período, a citricultura entrou em um período de estabilidade e passou para um novo ciclo de grandes desafios mantendo-se instável até 2005, quando tinha uma área plantada de 54.697 ha (EMDAGRO, 2012). Pode-se dizer que o processo de modernização agrícola acentuou a diferença social na agricultura, consolidando estrutura bimodal: agricultores empresariais altamente tecnificados, dirigidos para o mercado externo, e agricultores familiares que adotam formas tradicionais de utilização da força de trabalho familiar, incluindo o trabalho infantil como estratégia de produção (Lopes \& Costa, 2009). Ao longo dos anos, passando de uma atividade com forte presença no mercado interno de frutas "in natura" para uma commodity, cuja dependência das exportações de suco tornou-se vital para a continuidade do seu desenvolvimento, trouxe uma série de implicações que alguns citricultores não conseguiram se adequar e saíram da cadeia produtiva.

No período avaliado, entre 2010 e 2017, a área destinada ao cultivo de laranja no Brasil (Figura 2), manteve-se oscilado anualmente, variando de 844.469 a 629.770 ha, respectivamente, mas nunca retornando ao patamar inicial de 2010. Dentre os fatores que contribuem para essas oscilações temos a irregularidade climática, o desgaste dos pomares após grandes colheitas nos últimos anos e, principalmente, aos reduzidos investimentos que vêm sendo destinados à citricultura (DESEMBAHIA, 2008). Observa-se (Figura 3) que no ano de 2012 houve uma retração no acumulado de chuvas, finalizando o ano em apenas $752,3 \mathrm{~mm}$, sendo este valor $36,26 \%$ menor que o acumulado de 2011. Em 2013 houve uma melhora nas chuvas, com um acumulado de $1432,4 \mathrm{~mm}$. A média dos últimos 8 anos foi de $1112,5 \mathrm{~mm}$. O fator climático é um dos mais marcantes no Nordeste, onde a principal forma de cultivo é do tipo sequeiro. As chuvas são determinantes para a quantidade e a qualidade das safras. O resultado é 


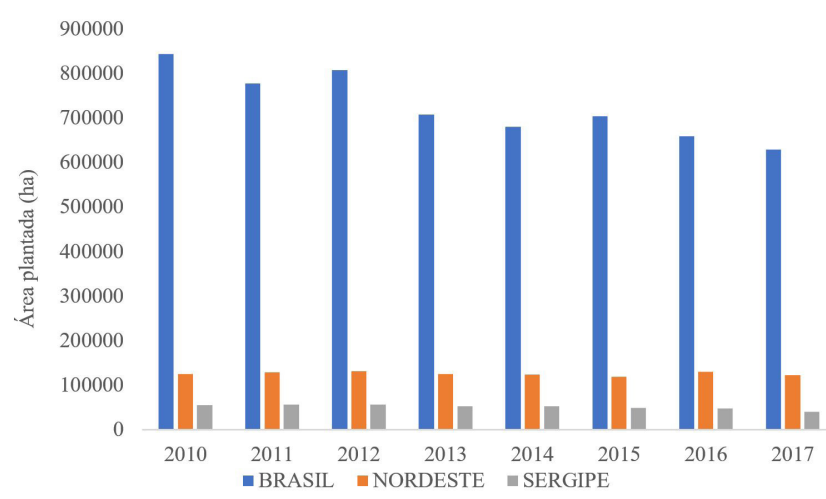

Figura 2. Histórico dos últimos oito anos da produção de laranja no Brasil, no Nordeste e em Sergipe, expresso em hectares.

Fonte: IBGE (2017).

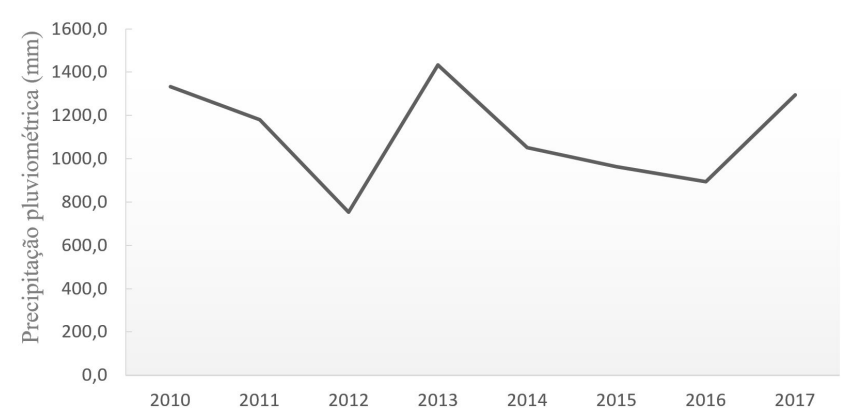

Figura 3. Histórico pluviométrico anual do estado Sergipe dos anos de 2010 a 2017.

Fonte: BDMEP - INMET, Estação: ITABAIANINHA - SE (OMM: 83195), Período solicitado dos dados: 01/01/2010 a 30/12/2017.

que alguns produtores têm migrado para outras culturas (como a pecuária, cultivo de cana-de-açúcar e do milho) ou simplesmente não investindo nos pomares existentes.

O cultivo de laranja no estado de Sergipe apresentou uma grande variação da área plantada com o passar dos anos, no período de 2010 a 2017, quando houve uma de redução da área cultivada. Em 2010 era 54.733 ha, o que correspondia a 43,8\% e 6,5\% da área plantada no Nordeste e no Brasil, respectivamente. Ao longo desses anos observa-se que apesar da área total plantada com laranja no país ter diminuído, a área plantada no Nordeste praticamente se manteve estável, com os números em 2010 de 125.068 ha e em 2017 de 122.807 ha. Atualmente o estado de Sergipe possui 40.200 ha, correspondente a $32,7 \%$ e 6,4\% da área plantada no Nordeste e no Brasil, respectivamente. A participação de cada estado produtor de laranja no Nordeste encontra-se na Figura 4.

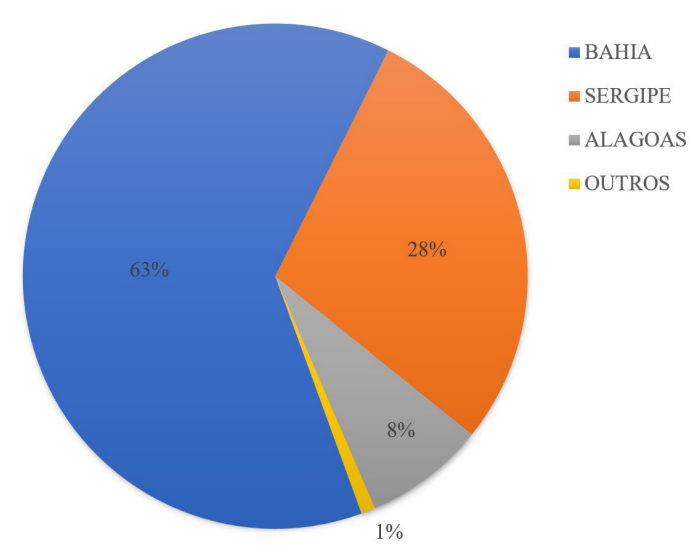

Figura 4. Porcentagem da participação dos estados do Nordeste na produção de laranja, expresso em hectares. Fonte: IBGE (2017).

Em São Paulo, que produz cerca de 12,3 milhões de toneladas de laranja, o que representa $73 \%$ da produção nacional (IBGE, 2017), o cultivo é feito, na sua maioria, em grandes áreas de produção, sendo que aproximadamente a metade é cultivada em área das próprias indústrias processadoras de suco, principal destino da laranja brasileira (DESER, 2007). Situação totalmente oposta à de Sergipe, onde é a agricultura familiar que responde maciçamente pela produção de laranja no estado, apesar das crescentes e graves dificuldades que vêm atingido mais diretamente os pequenos e os médios agricultores integrantes dessa categoria. O pequeno proprietário, o parceiro, o arrendatário e o posseiro, enquadrados na categoria de produtores tradicionais, trazem implicações sobre a racionalidade de uso do território. Tais fatores aliados ao processo de modernização da agricultura no estado, que são, como no resto do país, seletivas e que beneficia o agro complexo, os médios e grandes produtores, pois estes apresentam baixos riscos às agências financiadoras, levam a situação de que apenas um contingente mínimo de pequenos produtores rurais é beneficiado com políticas modernas de produção (Vasconcelos, 2015).

A laranja é produto moderno, todavia sua produção não é realizada em moldes completamente modernos. Perduram no território do citricultor sergipano resquícios de um pensamento arcaico. Assim como acontecia com a cana de açúcar no passado, quando os senhores de engenho desejavam aumentar a produção, expandiam os territórios de cana de açúcar para obter mais renda; atualmente a mentalidade é de aumentar a produtividade, conseguindo maior produção no mesmo espaço. 
Durante o período avaliado (Figura 5) houve uma retração muito significativa na produção sergipana, que em 2010 produziu 805.962 toneladas, ao passo que em 2017 foram colhidas apenas 453.933 toneladas, significando uma retração de 43,7\%. Esses valores refletiram na produção do Nordeste, que em 2010 foi 1.875 .669 toneladas e em 2017 foi 1.744 .673 toneladas. Um dos fatores que contribuiu para essa drástica redução foram os problemas fitossanitários, dentre eles destacamos o cancro cítrico, a

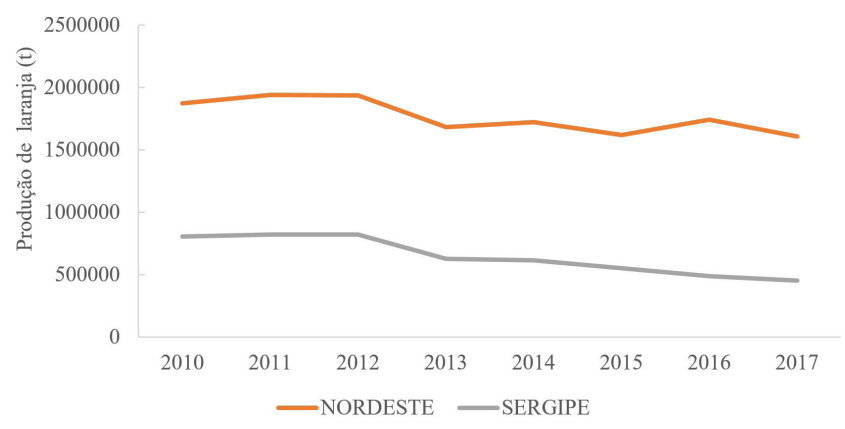

Figura 5. Histórico dos últimos 8 anos da produção de laranja no Nordeste e em Sergipe, expresso em toneladas. Fonte: IBGE (2017). clorose variegada dos citros (CVC) e a mosca negra dos citros (DESENBAHIA, 2008).

Dentro do estado de Sergipe, a região Centro-Sul apresenta os principais produtores de laranja do estado. Em 2010 o município com a maior área plantada era Itabaianinha, seguido dos munícipios de Cristinápolis e Lagarto com 5.110; 6.123 e 6.965 hectares, respectivamente. Atualmente (2017) Itabaianinha continua liderando com 5.200 (12\%), seguido por Salgado com 4.42 (11\%) e Cristinápolis com 4.742 (10,4\%) hectares.

Com relação a produção (Figura 6), segue classificação semelhante quanto as áreas. Em 2010 o município com a maior produção era Lagarto, seguido dos munícipios de Cristinápolis e Itabaianinha com 97.510, 91.845 e 76.650 toneladas de frutos, respectivamente. Atualmente (2017) Cristinápolis está liderando com 58.266 (12\%), seguido por Itabaianinha com 57.200 (12\%) e Lagarto com $49.791(10,2 \%)$ toneladas de laranja.

A mosca-negra-dos-citros (Figura 7), Aleurocanthus woglumi, é considerada por agricultores e técnicos locais, indubitavelmente, a praga mais devastadora de Sergipe. $\mathrm{Na}$ cultura dos citros a mosca negra acarreta danos diretos e indiretos prejudicando o desenvolvimento e a produção

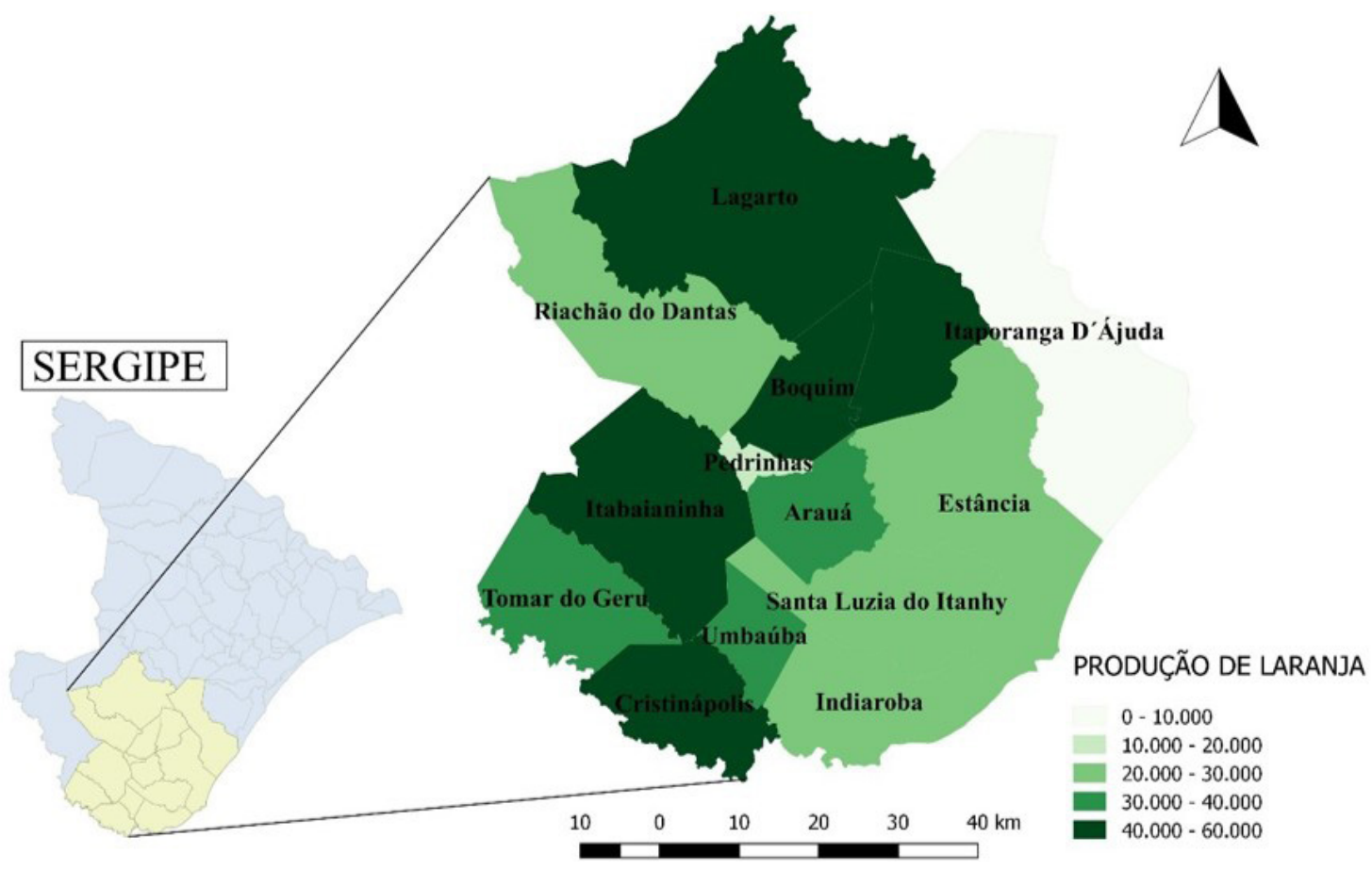

Figura 6. Cinturão citrícola sergipano:14 munícipios produtores localizados na região centro-sul. Mapa interativo de produção de laranja por município.

Fonte: Emdagro, 2018. Autor: Airan Miguel, 2018. 

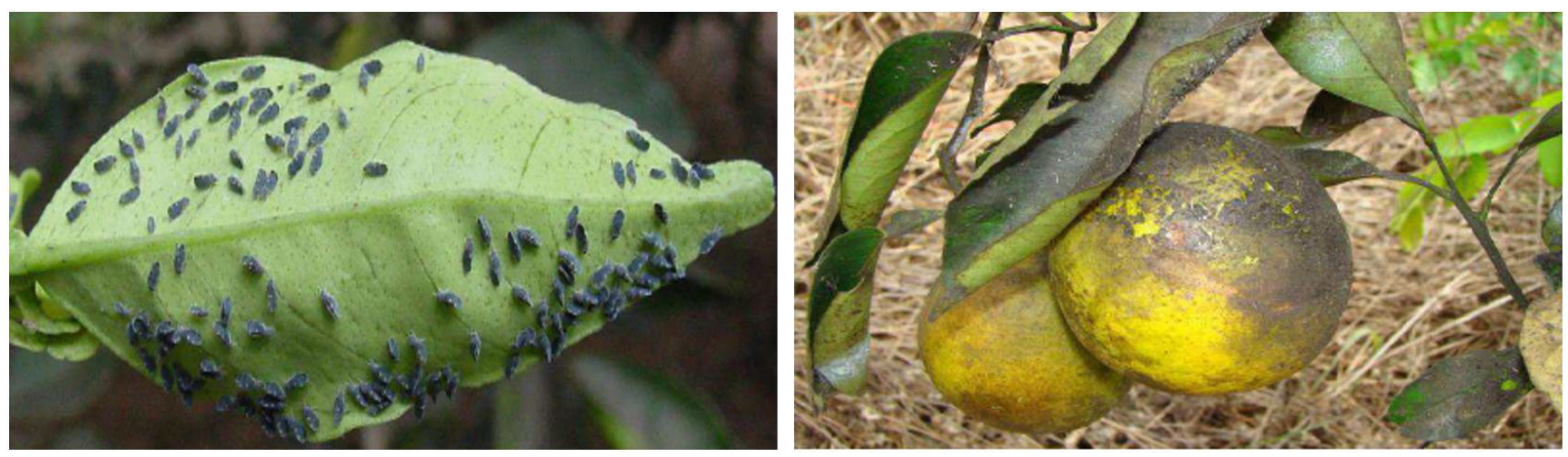

Figura 7. Adultos da mosca-negra-dos-citros (esquerda) A. woglumi em folha de citros (Raga \& Costa, 2013). Frutos e folhas com fumagina (direita) em plantas atacadas pela mosca-negra-dos-citros em Matinhas-PB.

Fonte: (Lopes \& Costa, 2009).

de pomares cítricos, além de restringir o comércio de locais de sua ocorrência para áreas livres da presença da praga.

Os danos diretos ocasionados pela mosca negra dos citros são decorrentes da sua alimentação diretamente no floema da planta retirando destas nutrientes debilitando-as, além de injetar toxinas presentes em sua saliva. De forma indireta, e, mais prejudicial, elimina secreção açucarada que induz ao aparecimento de fungos saprófitos que formam a fumagina (Capnodium citri) (Figura 7) (Oliveira et al., 1999). Pelo seu crescimento escuro e denso, podem reduzir consideravelmente quantidade de luz que incide sobre os órgãos clorofilados da planta, reduzindo a capacidade de fotossíntese (Cunha, 2003), diminuição da frutificação em até $80 \%$ (Barbosa \& Paranhos, 2004) e perdas de 20 a $80 \%$ na produção. Do ponto de vista econômico, a fumagina pode prejudicar a qualidade dos produtos agrícolas, alterando a sua aparência depreciando o fruto para a comercialização in natura.

A ampla distribuição geográfica da mosca negra no Brasil, num espaço de tempo relativamente curto, mostra que provavelmente, o homem tem sido seu principal agente dispersor, associado a outros fatores facilitadores de disseminação. Dessa forma, acredita-se que o transporte ao longo das rodovias, aliado a deficiência de fiscalizações, tenham sido o maior facilitador da disseminação dessa praga para os principais estados citricultores brasileiros.

Ao observar o decréscimo da produção (Figura 5), de 821.940 para 626.440 toneladas, entre os anos de 2012 e 2013 respectivamente, verifica-se que houve uma diminuição de 195.500 toneladas de laranja, correspondente a uma redução de $23,8 \%$. Percebe-se que o período coincide com a entrada da praga $A$. woglumi nos pomares sergipanos, e para intensificar mais as perdas, uma grave crise hídrica

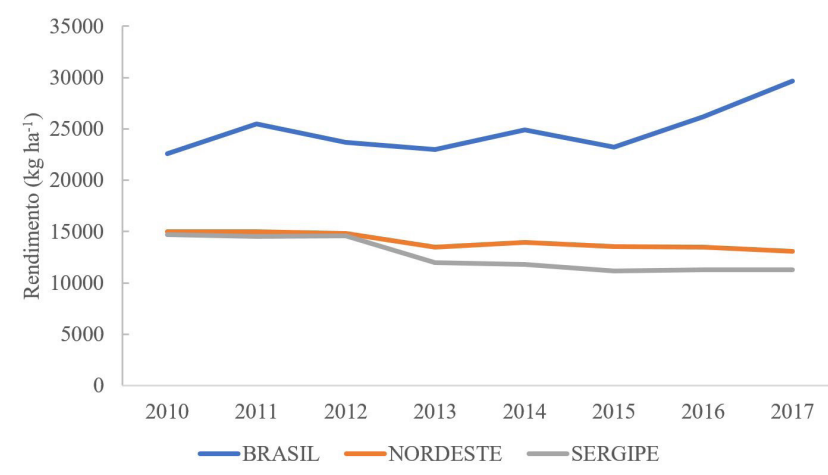

Figura 8. Histórico dos últimos 8 anos do rendimento da laranja no Brasil, Nordeste e em Sergipe, expresso em toneladas por hectare.

Fonte: IBGE (2017).

que ocorreu neste ano, ou seja, um acúmulo de fatores negativos que geraram uma das maiores crises para o setor.

Observa-se na Figura 8 que a produtividade sergipana de 14,58 toneladas por hectare em 2012 era compatível com a da região Nordeste, visto que os modos de cultivos, regime pluviométrico e severidade de pragas eram similares. A partir da safra 2013, com as problemáticas das chuvas e da praga $A$. woglumi a produtividade foi reduzida para 11,99 toneladas por hectare, o que equivale a uma redução de $18 \%$. Atualmente a produtividade está em 11,29 toneladas por hectare.

Apesar dos desafios enfrentados nos últimos anos, projeções do Ministério da Agricultura, Pecuária e Abastecimento (MAPA) indicam que a produção de laranjas deve aumentar na próxima década (Brasil, 2016). Visto isso, projeções para o setor citrícola sergipano (Figura 9) não muito favoráveis: as previsões indicam que 


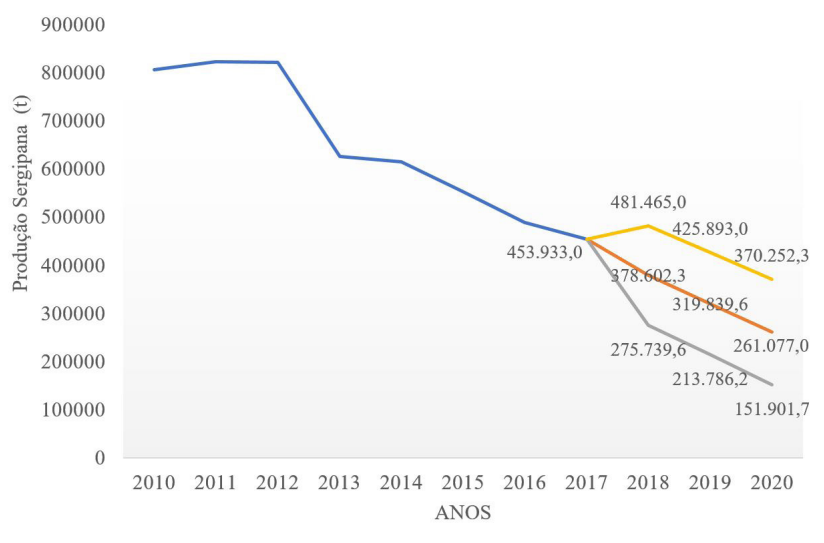

—Valores — Previsão — Limite de Confiança Inferior — Limite de Confiança Superior

Figura 9. Projeções do agronegócio citrícola do estado de Sergipe entre os anos de 2018 e 2020.

Fonte: IBGE (2017). Autor: Airan Miguel, 2018.

entre as safras de 2018 e 2020 a produção pode alcançar 370.252 toneladas em um cenário favorável, 261.077 toneladas em um cenário moderado e 151.902 toneladas em um cenário desfavorável. De acordo com Palmieri et al. (2016), os citricultores têm retomado ou planejado novos investimentos nos pomares. No mercado internacional, a oferta de laranja da Flórida (EUA), principal concorrente do Brasil, está em declínio, o que deve contribuir para manter as importações norte-americanas de suco brasileiro.

\section{CONCLUSÃO}

A área plantada no Nordeste praticamente se manteve estável, com os números em 2010 de 125.068 ha e em 2017 de 122.807 ha. Em 2010 a área plantada com laranja em Sergipe era 54.733 ha, o que correspondia a $43,8 \%$ e $6,5 \%$ da área plantada no Nordeste e no Brasil, respectivamente. Atualmente (2017) o estado de Sergipe possui 40.200 ha, correspondente a $32,7 \%$ e $6,4 \%$ da área plantada no Nordeste e no Brasil, respectivamente. O município de Itabaianinha apresenta 5.200 hectares cultivados com laranjas, que é a maior área ocupada com os pomares que representam $10,4 \%$ da área total ocupada no estado.

Durante o período entre 2010 e 2017 houve uma retração muito significativa na produção sergipana, com queda de 805.962 toneladas, para apenas 453.933 toneladas, significando uma retração de 43,7\%.

Ao observar o decréscimo da produção, de 821.940 para 626.440 toneladas entre os anos de 2012 e 2013 respectivamente, com redução de $23,8 \%$, percebe-se que o período coincide com a entrada da praga A. woglumi nos pomares sergipanos. Para intensificar mais as perdas, uma grave crise hídrica ocorreu em 2012, finalizando o ano em apenas $752,3 \mathrm{~mm}$, sendo este valor $36,3 \%$ menor que o acumulado de 2011.

Atualmente o município de Cristinápolis tem a maior produção do estado de Sergipe com 58.266 toneladas, representando $12 \%$ da produção sergipana.

Observa-se que a produtividade sergipana, de 14,72 toneladas por hectare em 2010, era compatível com a da região Nordeste. A partir da safra 2013 foi reduzida para 11,99 toneladas por hectare, numa redução de $18 \%$. Atualmente a produtividade está em 11,29 toneladas por hectare.

\section{REFERÊNCIAS}

Associação Nacional dos Exportadores de Sucos Cítricos - CITRUS BR. (2016). Estudo com os últimos dados do consumo global de suco de laranja. São Paulo: CITRUS BR.

Barbosa, F. R., \& Paranhos, B. J. (2004). Ameaça negra. Revista Cultivar Hortaliças e Frutas, 25(2), 33-39.

Boteon, M., Capello, F. P., Gomes, F. G., \& Viana, M. M. (2013). Citros - É viável continuar na citricultura? Hortifruti Brasil, 123(1), 10-26.

Boteon, M., Pagliuca, L. G., Palmieri, F. G., Sales, C. C. N., \& Ribeiro, R. G. (2015). Citros - Gestão sustentável. Hortifruti Brasil, 145(3), 10-20.

Brasil. Ministério da Agricultura Pecuária e Abastecimento - MAPA. (2016). Projeções do Agronegócio 2015/2016 a 2025/2026 (33-66 pp.). Brasília: MAPA.

Brasil. Ministério da Agricultura, Pecuária e Abastecimento. AGROSTAT: Banco de dados sobre comércio exterior. (2018). Recuperado em 17 de janeiro de 2018, de http:// agrostat.agricultura.gov.br

Cunha, M. L. A. (2003). Distribuição, hospedeiros, densidade populacional, aspectos biológicos e controle químico da mosca negra dos citros (Aleurocanthus woglumi Ashby) nas condições do Estado do Pará (Dissertação de mestrado). Universidade Federal Rural da Amazônia, Belém.

Departamento de Estudos Sócio-Econômicos - DESER. (2007). A cadeia produtiva da laranja: estudo exploratório (pp. 09-16). Curitiba: Deser.

Diretoria de Desenvolvimento de Negócios - DESENBAHIA. Gerência de Estudos e Assessoria Unidade de Estudos 
Econômicos e Pesquisas. (2008). Relatório de Mercado de Citrus: laranja (pp. 12-16). Salvador: Desenbahia.

Empresa Brasileira de Pesquisa Agropecuária-EMBRAPA. (2015). Citricultura no estado de Sergipe. Recuperado em 01 de janeiro de 2017, de https://www.embrapa. br/web/portal/busca-de-noticias/-/noticia/2414294/ artigo---citricultura-no-estado-de-sergipe.

Empresa Brasileira de Pesquisa Agropecuária-EMBRAPA. Departamento Estadual de Desenvolvimento Agropecuário de Sergipe. (2007) Aspectos Técnicos dos Citros em Sergipe (pp. 87). Aracaju: Embrapa Tabuleiros Costeiros.

Empresa de Desenvolvimento Agropecuário do Estado de Sergipe-EMDAGRO. (2012). Levantamento fitossanitário de detecção da mosca negra dos citros no Estado de Sergipe (7 pp.). Aracaju: EMDAGRO.

Empresa de Desenvolvimento Agropecuário do Estado de Sergipe-EMDAGRO. Safra dos Principais Produtos Agrícolas - 2018. Aracaju: EMDAGRO (2018). Recuperado em 30 de janeiro de 2018, de https://www.emdagro. se.gov.br/

Empresa Brasileira de Pesquisa Agropecuária-EMBRAPA. (2015). Citricultura no estado de Sergipe. Recuperado em 01 de janeiro de 2017, de https://www.embrapa. br/web/portal/busca-de-noticias/-/noticia/2414294/ artigo---citricultura-no-estado-de-sergipe.

Federação da Agricultura do Estado do Paraná - FAEP. (2016). Com mais da metade da produção mundial de suco de laranja, frutas citricas no Brasil potencializam o PIB nacional. Recuperado em 30 de janeiro de 2018, de https://www.cnabrasil.org.br/noticias/com-mais-dametade-da-produ $\% \mathrm{C} 3 \% \mathrm{~A} 7 \% \mathrm{C} 3 \% \mathrm{~A} 30-$ mundial-de-sucode-laranja-frutas-c $\% \mathrm{C} 3 \% \mathrm{ADtricas}-n o-b r a s i l-p o t e n c i a l i z a m-$ o-pib-nacional

Food and Agriculture Organization of the United Nation - FAO. (2017). Crops. Recuperado em 10 março de 2017, de http://www.fao.org/brasil/noticias/detail-events/ es/c/1040741/

Fundo de Defesa da Citricultura - FUNDECITRUS. (2016). Sinal positivo: pela primeira vez, crescimento de HLB é interrompido por conta do manejo dos pomares e eliminação das plantas doentes. Revista Citricultor, 37(1), 21-27.

Instituto Brasileiro de Geografia e Estatística - IBGE. (2017). Indicadores IBGE - Estatística da Produção Agrícola de 2017. Recuperado em 10 agosto de 2018, de https://sidra.ibge.gov.br/pesquisa/pam/tabelas
Lopes, E. S. A., \& Costa, J. E. (2009). Territórios rurais e agricultura familiar no Nordeste (vol 1., 273 pp.). Aracaju: EDUFS.

Maciel, I. L. (2015) Status sanitário da mosca negra dos citros no Brasil (Dissertação de mestrado). Universidade Federal de Viçosa, Viçosa.

Microsoft Support Office. (2018). Escolher a melhor linha de tendência para seus dados. Recuperado de 20 de junho de 2018, de https://support.office.com/pt-br/article/ escolher-a-melhor-linha-de-tend $\% \mathrm{C} 3 \%$ AAncia-paraseus-dados-1bb3c9e7-0280-45b5-9ab0-d0c93161daa8.

Neves, M. F., \& Trombin, V. G. (2016). Série consumo de suco de laranja. Citrus BR, 8(2), 45-58.

Oliveira, M. R. V., Silva, C. C. A., \& Navia, D. (1999) Praga Quarentenária A1: A mosca negra dos citros, Aleurocanthus woglumi Ashby (Hemiptera: Aleyrodidae) (Comunicado Técnico, 40, 7 pp). Brasília: EMBRAPA.

Palmieri, F. G., Cappello, F. P., Boteon, M., \& Pagliuca, L. G. (2016). Citros - Caminhos de citricultura no póscrise. Hortifruti Brasil, 156(1), 10-19.

Raga, A., \& Costa, V. A. (2013). Mosca Negra dos Citros. Citrus Research \& Technology, 34(2), 57-63.

Silva, A. G. (2005). Mosca negra dos citros, Aleurocanthus woglumi Ashby, praga potencial para a citricultura brasileira. In L. S. Poltronieri, D. R. Trindade, \& I. P. Santos. Pragas e doenças de cultivos amazônicos (379 pp.). Belém: Embrapa Amazônia Ocidental.

United States Department of Agriculture - USDA. (2018). Agricultural Projections. Recuperado em 23 fevereiro 2019, de http://usda.mannlib.cornell.edu/usda/ers/94005/2018/ usda-ag-projections-2018.pdf

Vasconcelos, C. A. (2015). Modernização x agricultura familiar: dialética contraditória na citricultura sergipana no nordeste do brasil. Acta Geográfica, 9(1), 37-50.

Recebido: Novembro 21, 2018 Aceito: Setembro 11, 2019

Como citar: Panta, A. M. S., \& Santos Sobrinho, V. R. A. 2019. Agronegócio da citricultura sergipana entre 2010 a 2017. Citrus Research \& Technology, 40, e1050. https://doi.org/10.4322/crt.17419. 